\title{
Knowledge Transfer in Science Education: The Case for Usability-Based Knowledge Visualization Guidelines
}

\author{
Olakumbi A. Fadiran ${ }^{(凶)}$, Judy van Biljon, and Marthie A. Schoeman \\ School of Computing, University of South Africa, Pretoria, South Africa \\ olakumbi@gmail.com, \{vbiljja, schoema\}@unisa.ac.za
}

\begin{abstract}
There is growing evidence that visualization aids knowledge transfer. However, the cases where learners have been actively involved as cocreators of knowledge visualization aids are limited. Furthermore, employing knowledge visualization for teaching and learning in high-school science have been proposed but empirical evidence of the effect on knowledge transfer is limited. The purpose of this study is to report on the knowledge transfer effect of applying usability-based knowledge visualization guidelines. A design-based research methodology guided by pragmatism was applied. The data capturing methods include a questionnaire-based survey, interviews and observations. The results suggest that the use of knowledge visualization can support knowledge transfer and the students' learning experience in secondary school education, but more research is required to confirm this. The contribution of this paper is to add to the emerging discourse on the use of knowledge visualization for teaching and learning, and to report on how knowledge visualization guidelines can be used in practice.
\end{abstract}

Keywords: Knowledge visualization - Usability-based knowledge visualization guidelines $\cdot$ Knowledge transfer

\section{Introduction}

Digital technology is widely used for educational purposes. In this scenario a salient duty of a teacher is to assist in the transfer of knowledge to students in a meaningful and understandable manner [1]. To aid this role, teachers use their proficiency to choose and use teaching materials such as lecture notes, textbooks, multimedia tools etc. [2], while learners are expected to engage with these study materials. Teachers often employ specific strategies to create and transfer knowledge, and one such technique is visualization [3, 4]. Visualization involves the use of images to transfer data, information or knowledge [5,6]. These are often created by teachers, educational, learning and instructional designers for teaching and learning [7], with minimal or negligible contribution from learners. According to Bada [8], it benefits learners to be co-creators of their learning experience. Actively involving students in knowledge visualization $(\mathrm{KV})$ is one way of compelling them to engage with learning material and to achieve knowledge transfer (KT). In addition, producing KV allows learners to demonstrate their knowledge acquisition. The problem is a lack of knowledge 
visualization guidelines and standards in the extant literature, this hampers evidencebased implementation of knowledge visualization initiatives.

This paper is an extension of the work done by Fadiran, van Biljon and Schoeman [9], which focused on evaluating the usefulness of usability-based knowledge visualization guidelines for high school science learners to create, illustrate and internalise the new knowledge that they are expected to become proficient in. For this paper, the investigation focuses on learners' experience of $K T$ while applying the usability-based knowledge visualization guidelines in creating images to demonstrate their knowledge acquisition, as well as the effect on the images created by learners when they apply the usability-based knowledge visualization guidelines. To investigate learners' experience of KT via the use of usability-based knowledge visualization guidelines, a group of science learners in high school were asked to create visual diagrams to illustrate the rocket launch phase. Usability-based knowledge visualization guidelines was introduced to learners after which the initial images created by learners were revised to meet these guidelines. The exercise aims to investigate the impact of each guideline on the images created by the learners when using the guidelines to improve their knowledge representation to demonstrate their knowledge acquisition and transfer. The remainder of the paper gives an overview on: what KV entails; KT; how Human Computer Interaction (HCI) usability guidelines was used to inform KV principles, culminating in the usability-based knowledge visualization guidelines artefacts developed for this study; and the effect of usability-based knowledge visualization guidelines on images produced by learners as well as learners experience of KT through KV.

\section{Literature Review}

Visualization is defined as the technique of changing measurable data into visual images in a manner that unveils their patterns and relations $[5,10]$. The subsequent sections describe KV, KT and usability-based knowledge visualization guidelines in relation to this study.

\subsection{What Is Knowledge Visualization?}

Knowledge visualization consists of exploring the use of visual representations in the form of graphs, diagrams, drawings, sonographs etc. to enhance knowledge creation and transfer between at least two people [11, 12]. Eppler views KV as the use of graphics to create, integrate and administer knowledge [13]. Van Biljon and Renaud noted that the primary aim of $\mathrm{KV}$ is knowledge transfer in contrast to information visualization which aims to support pattern identification [7]. In summary, KV entails the creation of knowledge, using available visual resources in a manner that is understandable and communicable to other people.

\subsection{Knowledge Transfer}

The term 'knowledge transfer' according to [14] "involves both the sharing of knowledge by the knowledge source and the acquisition and application of knowledge 
by the recipient". KT can be defined as the transmission of knowledge from one place, person or ownership to another [15].

According to [16], teachers can impart information and knowledge to learners in the process of teaching and learning. However, for learners to internalise the information they need to rebuild the knowledge. $\mathrm{KV}$ is an approach to assist in the process of rebuilding knowledge. In addition, teachers can use KV to transfer easily understandable visual metaphors since the brain can process images more easily than text [17].

\subsection{Usability-Based Knowledge Visualization Guidelines}

A systematic literature review (SLR) was used to extract design principles from the field of information and knowledge visualization from literature, as well as HCI usability guidelines. The SLR was chosen as a replicable, open, impartial and comprehensive protocol [18, 19]. The mapping of $\mathrm{KV}$ principles onto HCI usability guidelines is explained in Fadiran et al. [9]. That mapping is the theoretical basis of the usability-based knowledge visualization guidelines developed for this study. The guidelines relevant to this study are: Abstract (or compress) the knowledge, Easy to understand, Know your data, Clarity, Use natural representations, Legend, Use of colours, Avoid decorations, Relationship between concepts clearly shown, Simplicity and Clear boundaries.

\section{Research Methodology}

A design-based research (DBR) methodology was employed in this study with pragmatism as the philosophy. DBR was selected as it: relates with circumstances in the real world [20, 21]; and incorporates the application of data triangulation which enhances the reliability and internal validity of findings [22]. A research group comprising a teacher and science learners in high school was set up and organized to collect information about the impact of usability-based knowledge visualization guidelines to support KT. The approach promoted the interaction of teachers and learners and allowed us to obtain qualitative and quantitative information from the participants.

\subsection{Procedure}

Twenty-one representative participants (18 learners, 1 educator and 1 usability tester) took part in the research. Participants were selected based on convenience sampling. The learners (12 males) were high school science students attending schools in the Gauteng province (private and public). This ensured that a cross-section of participants has been chosen as advocated by [23]. A standard introduction and explanation of the purpose of the research was delineated to participants at the beginning of the session. The phases of a rocket launch were taught, and learners were requested to provide a diagrammatic representation of the topic. Learners created their first image after which they were introduced to usability-based knowledge visualization guidelines. The learners created a second image by applying these guidelines to the initial image. 
The link between HCI usability guidelines and knowledge visualization can be summarized as follows, for more detail please see Fadiran et al. [9].

1. Abstract: Extracting essential components and their relationships from a body of knowledge [24, 25] distinguish relevant information [26, 27].

2. Present overview and details on demand: This ease navigation and support the search task [28].

3. Consistency: Using the same specific graphic design element to indicate a specific concept or relationship in a visualization and combining distinct concepts and ideas adheres to standards [26, 27].

4. Easy to understand: Presenting the visualization in a simple comprehensive manner requires no prior knowledge of the content [29, 30].

5. Know your data: Comprehending and exploring the data domain while being aware of previous and related work [27] allows the designer to create meaningful and appropriate images [30, 31].

6. Clarity: Clarifying goals, objectives and outcomes [26] and the use of defined symbols avoid ambiguity [32, 33].

7. Know your audience: User-centred design, understanding the audience's needs, abilities, interests, and expectations [27] are fundamental concepts in HCI.

8. Use natural representations: Associating the visualization with the real world allows a recognition-based approach to interpreting images [34, 35].

9. Legend: A supplementary object that offers detailed explanations of the symbols provides multiple views of the data [36].

10. Use of colours: Colour can differentiate relationships, beautify, group, map and classify images [24, 31, 37]

11. Avoid decorations: Avoid the use of unrelated elements [32, 34].

12. Relationship between concepts clearly shown: Use links to demonstrate relationships between concepts [33, 38].

13. Motivate audience: Present the knowledge in an engaging manner [26].

14. Simplicity: Minimize the number of concepts on each level of visualization to $7 \pm 2$ objects [33].

15. Dual coding: The use of text and graphics to explain the same construct [39] allows processing of information with both textual and visual representation [40].

16. Clear boundaries: Navigate and embed knowledge within a domain [41].

After the introduction to the visualization guidelines some learners edited their initial image while others resolved to creating a new image. The two images each learner created were then compared and evaluated to determine the effect of the guidelines on knowledge acquisition and transfer. Quantitative and qualitative analysis was conducted to: compare the two images produced by each learner to demonstrate their knowledge acquisition; evaluate learners' marks for the respective images produced to demonstrate their knowledge acquisition before and after a brief on using usabilitybased knowledge visualization guideline; and document their experience of using KV to demonstrate their knowledge acquisition. 


\section{Results and Findings}

Previous research proposed a set of validated KV guidelines towards the theory and practice of using $\mathrm{KV}$ in teaching and learning [9]. Effective KT from teachers to learners influence learners' performance and satisfaction [2]. Figure 1 shows the difference in the marks of learners before and after the brief on usability-based knowledge visualization guidelines. The marks for the visualization created after the brief is consistently higher which suggests a positive influence on KT. However, we acknowledge that there are other contributing factors and the limitation of the sample size. Therefore, we can only conclude that the results merit further investigation. Table 1 shows the post survey reaction of learners to the use of KV in teaching and learning. A large percentage of the learners think the use of $\mathrm{KV}$ influenced their knowledge acquisition and transfer.

\subsection{Analysis}

From Fig. 1, it can be observed that the average marks of learners increased from 52\% to $56 \%$ following the brief on usability-based knowledge visualization guidelines.

Notably, the study content was not revisited before the second visualization was created. Learners who did not feel a need to modify their images show a minimum percentage difference of $0 \%$ in marks while the maximum was $12 \%$ for a learner who took advantage of the usability-based knowledge visualization guidelines to modify the initial image produced.

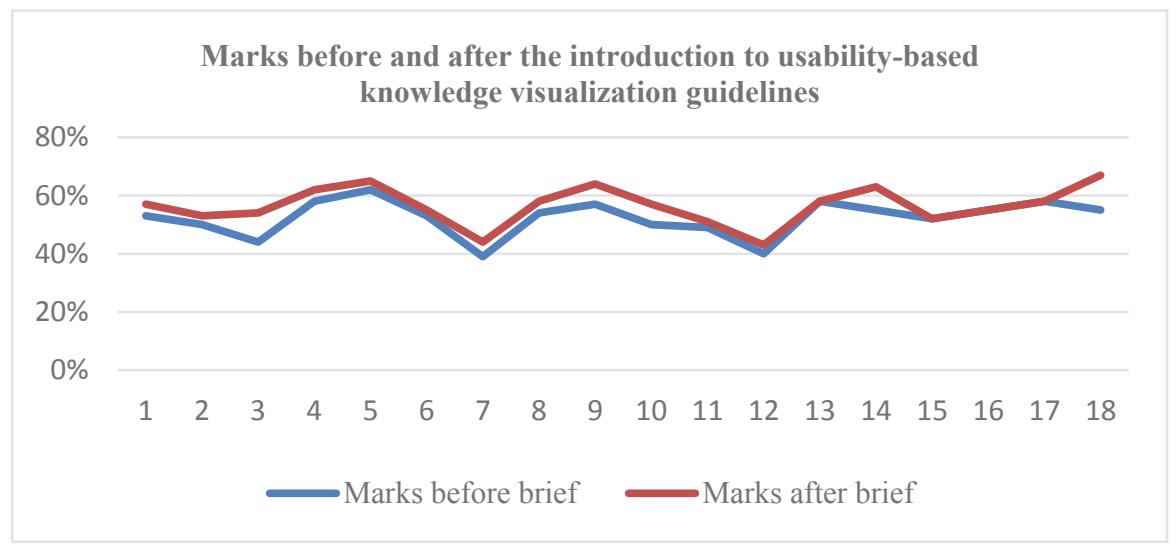

Fig. 1. Learners' marks before and after the brief on usability-based knowledge visualization guidelines

Table 1 depicts learners' post survey reaction to the use of KV in teaching and learning. All learners indicated that they had used images before to represent school work in form of sketches, graphs, charts, tables and pictures while $61 \%$ agreed that implementing the usability-based knowledge visualization guidelines influenced their 
final diagram. Furthermore, $83 \%$ stated that they will consider the usability-based knowledge visualization guidelines to exhibit knowledge transfer to others. Finally, $94 \%$ of the learners believe the use of KV influenced their knowledge acquisition.

Table 1. Post survey reaction of learners to the use of knowledge visualization

\begin{tabular}{l|l|l|l|l}
\hline Response & $\begin{array}{l}\text { Have you } \\
\text { ever used } \\
\text { images to } \\
\text { represent } \\
\text { your school } \\
\text { work? }\end{array}$ & $\begin{array}{l}\text { Did the use of } \\
\text { KV guidelines } \\
\text { had any effect } \\
\text { on your final } \\
\text { diagram? }\end{array}$ & $\begin{array}{l}\text { Will you consider } \\
\text { using the KV as a } \\
\text { means of exhibiting } \\
\text { knowledge transfer } \\
\text { to others? }\end{array}$ & $\begin{array}{l}\text { Do you think the } \\
\text { use of KV had } \\
\text { any effect on your } \\
\text { knowledge } \\
\text { acquisition? }\end{array}$ \\
\hline Yes & $100 \%$ & $61 \%$ & $83 \%$ & $94 \%$ \\
\hline No & - & $39 \%$ & $17 \%$ & $6 \%$ \\
\hline
\end{tabular}

Some of the explanations given by learners are shown below:

- Effect of $K V$ on the final diagram includes: Images produced are clearer and simpler, useful in abstraction, improves image quality.

- Effect of $K V$ on knowledge acquisition includes: Easier studying, learning new knowledge, easier to understand new topics, promotes memorability, simplifies learning, clarity.

Images produced by learners before and after the introduction to $\mathrm{KV}$ guidelines were compared and the observations are described in the next section. The analysis was carried out on the KV guidelines presented in Sect. 3.1. The subsequent sections show observations made on samples of some of the learners' visualizations before and after introducing the learners to usability-based knowledge visualization guidelines.

\subsection{Guidelines with Major Effect on the Final Diagram}

The guidelines 'Know your data, Clarity, Easy to understand, Use of colours, Clear boundaries, Legend and Relationship between concepts clearly shown' had a noticeable effect on learners' final visualizations. Figure 2 is a sample of how a learner incorporated some of these guidelines into his/her final diagram. In the new image produced, the learner added a title added to the visualization (Easy to understand) as well as a description of the symbols used (Legend). No learners included a legend in their initial visualization. However, the brief prompted half of them to add a legend, solving their need to give a meaningful explanation of the symbols used and thereby aiding other usability-based knowledge visualization guidelines. The clarity of the boundaries may be dependent on the context of the topic being visualised i.e. it is less relevant for visualizations in the same domain.

The 'Easy to understand' guideline had a high level of compliance which was influenced by the compliancy of other guidelines, suggesting inter-guideline dependencies. Although the 'Use of colours' guideline had a noticeable increase in compliance after the brief on usability-based knowledge visualization guidelines, a number 
of participants were cautious in their application of this principle to avoid compromising other principles such as 'Avoid decorations'. For others, it was a quick resolve to implement the 'Clear boundaries' principle.

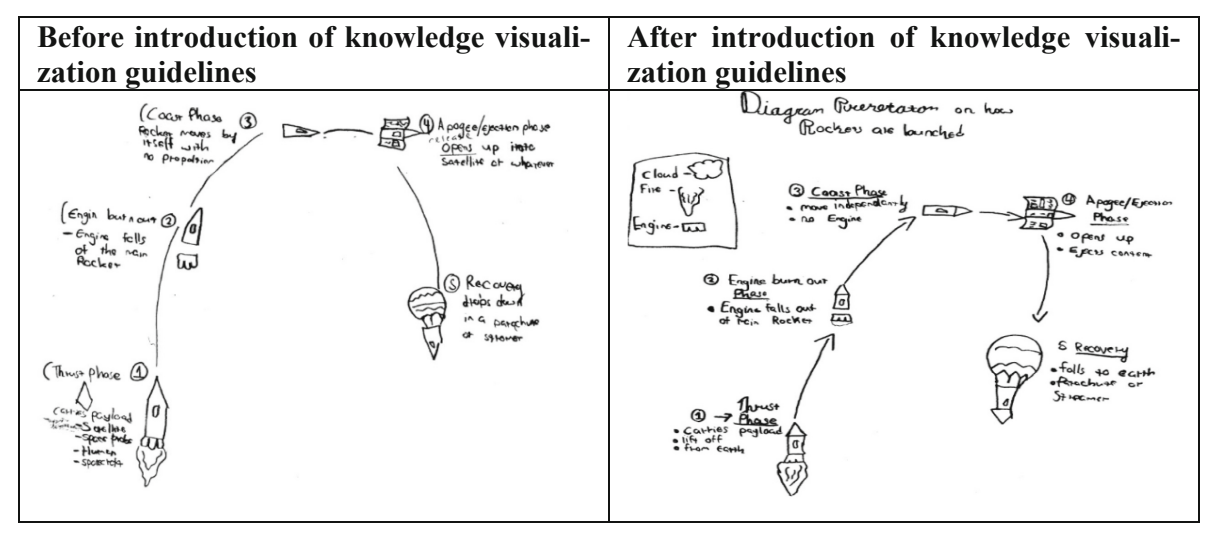

Fig. 2. Sample of learners' visualization before and after usability-based knowledge visualization guidelines brief

\subsection{Guidelines with Little Effect on Final Diagrams}

The guidelines 'Abstract knowledge, Avoid decorations and Simplicity' had negligible visible influence on learners' final diagram. Figure 3 is another sample of images produced by a learner with the brief on usability-based knowledge visualization guidelines having little effect on the final image produced.

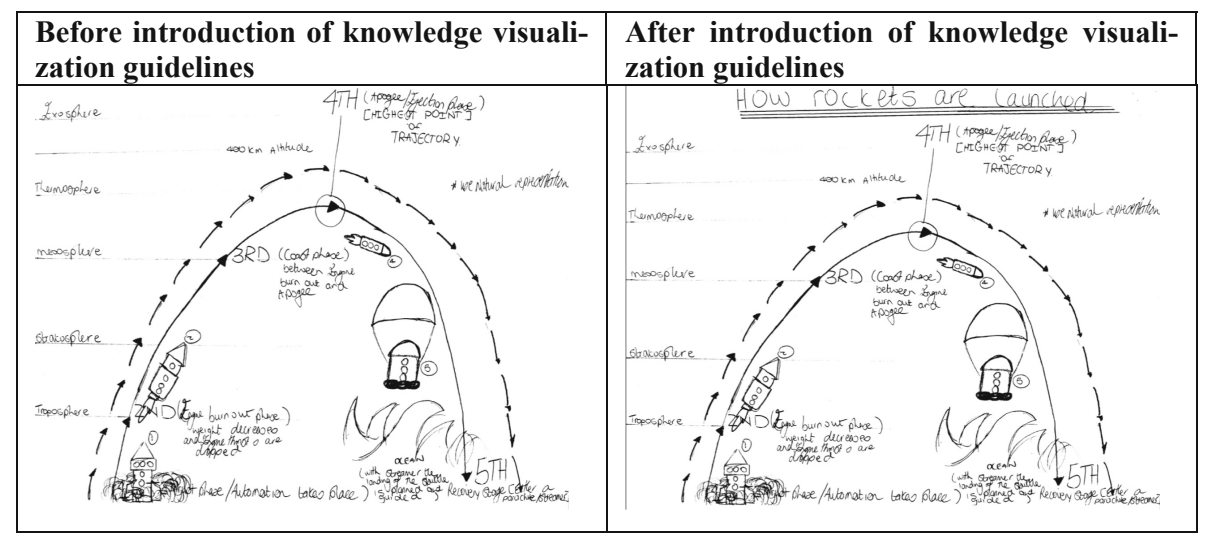

Fig. 3. Sample of learners' visualization before and after usability-based knowledge visualization guidelines brief 
From observation, the 'Avoid decorations' principle did not make a significant difference in the final images created by learners, especially after a legend clarified symbols used. The visualizations produced by most learners was void of symbols not related to the content of the study. Also, the 'Abstract knowledge' and 'Simplicity' principles appeared to have little impact on the final images created by learners. In both cases, this could be due to time constraints which caused learners to include only the most important constructs visualised in their simplest form. These principles could become more prominent when visualizations have been created over a period.

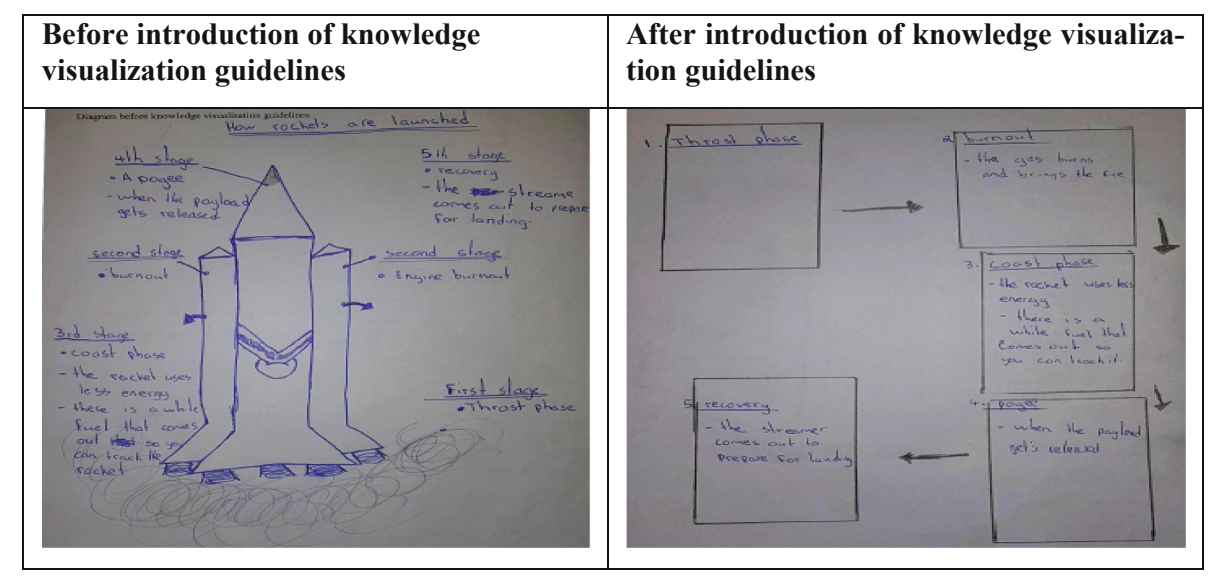

Fig. 4. Sample of learners' visualizations before and after the introduction of the guidelines

\subsection{Guideline with Reduced Compliance (Use of Natural Representation)}

Learners in the research group had personal preferences in using visualization to represent knowledge. Some learners believed an artistically inclined individual is better suited to exploring the concept of visualization with the majority of the learners agreeing that they are willing to use images to represent and transfer knowledge. In addition, some learners were concerned that their representation of the real world may violate another principle i.e. the Avoid decorations principle.

A designer's background can influence their use of natural representation. Figure 4 shows a learner producing a new visualization void of images. The initial incorporated the guideline 'Use of natural representation' while the latter implemented 'Avoid decorations'. 


\section{Challenges and Limitations}

The challenges and limitations encountered during this study includes: factors that may have influenced learners' conformity to usability-based knowledge visualization guidelines i.e. disorientation, information and cognitive overload, time constraint; the risk of possible distortion of reality through misinterpretations; the diversity in learners literacy skills and learning styles; inadequate automatization support in the process of creating $\mathrm{KV}$; and number of participants.

\section{Summary and Future Work}

This paper contributes to the discourse on how usability-based knowledge visualization guidelines could provide support in improving knowledge acquisition and transfer amongst high school science learners. Learners experienced the use of KV in their knowledge acquisition and transfer as positive. The findings indicate that most of the guidelines considered in this study provided various degrees of impact on the images produced by learners, showing evidence of the effect of the guidelines on knowledge transfer. This correlates with findings from literature indicating that $\mathrm{KV}$ can be used to: improve learning abilities; improve communication and interaction around cognitive processes; and improve learners' attitude towards learning [7, 38, 42, 43].

Future work would be to repeat the research with a larger number of participants and in other school subjects in order to refine KV guidelines and to study the effect of using the guidelines to achieve and enhance knowledge transfer. In addition, the differences in how learners of previous generations and the Net Generation approaches visualization and use it for teaching and learning needs to be investigated.

Acknowledgement. This paper is based on the research supported by the South African Research Chairs Initiative of the Department of Science and Technology and National Research Foundation of South Africa (Grant No. 98564).

\section{References}

1. Stürmer, K., Könings, K.D., Seidel, T.: Declarative knowledge and professional vision in teacher education: effect of courses in teaching and learning. Br. J. Educ. Psychol. 83(3), 467-483 (2013)

2. Ahmad, K.B., Ahmad, M., Rejab, M.: The influence of knowledge visualization on externalizing tacit knowledge. In: Proceeding of the International Conference on Advanced Science Engineering and Information Technology, pp. 124-128 (2011)

3. Strakhovich, E.: Ontological engineering in education: tools for knowledge transfer and knowledge assessment. In: International Conference on Advanced Learning Technologies, pp. 714-715 (2014)

4. Wang, P., Wu, P., Wang, J., Chi, H., Wang, X.: A critical review of the use of virtual reality in construction engineering education and training. Int. J. Environ. Res. Public Health Rev. 15(6), 1204 (2018) 
5. Manovich, L.: What is visualization? J. Initiat. Digit. Humanit. Media Cult. 2(1), 1-32 (2010)

6. Ursyn, A.: Knowledge Visualization as a Teaching Tool. Visual Approaches to Cognitive Education With Technology Integration, pp. 1-23. IGI Global, Hershey (2018)

7. van Biljon, J., Renaud, K.: Facilitating knowledge visualisation as communication and knowledge transfer mechanism in postgraduate learning. In: Brown, T.H., van der Merwe, H.J. (eds.) mLearn 2015. CCIS, vol. 560, pp. 156-171. Springer, Cham (2015). https://doi. org/10.1007/978-3-319-25684-9_12

8. Bada, S.O.: Constructivism learning theory: a paradigm for teaching and learning. J. Res. Method Education. 5(6), 66-70 (2015). https://doi.org/10.9790/7388-05616670

9. Fadiran, O.A., van Biljon, J., Schoeman, M.A.: How can visualization principles be used to support knowledge transfer in teaching and learning? In: 2018 Conference on Information Communications Technology and Society, ICTAS 2018 - Proceedings, pp. 1-6 (2018)

10. Munzner, T.: Visualization. In: Shirley, P., et al. (eds.) Fundamentals of Graphics, ch. 27, 3rd edn., pp. 675-707 (2009)

11. Yusoff, Z., Katmon, S.A., Ahmad, M.N., Miswan, S.H.M.: Visual representation: enhancing students's learning engagement through knowledge visualization. In: International Conference on Informatics and Creative Multimedia, pp. 242-247 (2013)

12. Chaolong, J., Hanning, W., Lili, W.: Research on visualization of multi-dimensional realtime traffic data stream based on cloud computing. Procedia Eng. 137, 709-718 (2016)

13. Eppler, M.J.: What is an effective knowledge visualization? Insights from a review of seminal concepts. In: Proceedings of the International Conference on Information Visualization, pp. 3-12 (2011)

14. Wang, S., Noe, R.A.: Knowledge sharing: a review and directions for future research. Hum. Resour. Manag. Rev. 20(2), 115-131 (2010)

15. Sarala, R.M., Junni, P., Cooper, C.L., Tarba, S.Y.: A sociocultural perspective on knowledge transfer in mergers and acquisitions. J. Manag. 42(5), 1230-1249 (2016)

16. Zhong, D., Zhang, J.: Knowledge visualization-an approach of knowledge transfer and restructuring in education. In: International Forum on Information Technology and Applications, IFITA 2009, vol. 3, pp. 716-719 (2009)

17. Eppler, M.J., Burkhard, R.A.: Visual representations in knowledge management: framework and cases. J. Knowl. Manag. 11(4), 112-122 (2007)

18. Oates, B.J., Edwards, H.M., Wainwright, D.W.: A model-driven method for the systematic literature review of qualitative empirical research. In: ICIS 2012 Proceedings, China, pp. 118 (2012)

19. Xiao, Y., Watson, M.: Guidance on conducting a systematic literature review. J. Plann. Educ. Res. 39(1), 93-112 (2019)

20. Bakker, A., van Eerde, D.: An introduction to design-based research with an example from statistics education. In: Bikner-Ahsbahs, A., Knipping, C., Presmeg, N. (eds.) Approaches to Qualitative Research in Mathematics Education. Advances in Mathematics Education, pp. 429-466. Springer, Dordrecht (2015). https://doi.org/10.1007/978-94-017-9181-6_16

21. Anderson, T., Shattuck, J.: Design-based research: a decade of progress in education research? Educ. Res. Rev. 41(1), 16-25 (2016)

22. Stemberger, T., Cenci, M.: Design-based research in an educational research context. J. Contemp. Educ. Stud./Sodobna Pedagogika 65(1), 62-75 (2014)

23. Krueger, R.A., Casey, M.A.: Participants in a focus group. In: Focus Groups: A Practical Guide for Applied Research, pp. 63-84 (2009). https://www.sagepub.com/sites/default/files/ upm-binaries/24056_Chapter4.pdf

24. Scarpato, N., Maria, P., Pazienza, T.: Knowledge-based visualization systems. University of Rome Tor Vergata (2012) 
25. Kumar, S.: A review of recent trends and issues in visualization. Int. J. Comput. Sci. Eng. (IJCSE) 8(3), 41-54 (2016)

26. Ssemugabi, S., De Villiers, R.: Effectiveness of heuristic evaluation in usability evaluation of e-learning applications in higher educ. S. Afr. Comput. J. 45(45), 26-39 (2010)

27. Ferreira, D.J.: Human computer interaction teaching method to encourage creativity. In: The Seventh International Conference on Software Engineering Advances (ICSEA), pp. 472-478 (2012)

28. Burigat, S., Chittaro, L.: On the effectiveness of overview + detail visualization on mobile devices. IEEE Trans. Visual Comput. Graphics 17(2), 1-18 (2013)

29. Zhou, Y., Yin, L., Wang, L.: A research for the classification of knowledge visualization. In: International Conference on Electrical and Control Engineering, pp. 6235-6238 (2011)

30. Figueiras, A.: How to tell stories using visualization. In: 8th International Conference on Information Visualization, pp. 18-26 (2014)

31. Ware, C.: Information Visualization: Perception for Design, 3rd edn. Elsevier, Amsterdam (2012)

32. Bresciani, S., Eppler, M.J.: The pitfalls of visual representations. SAGE Open 5(4), 1-14 (2015). http://journals.sagepub.com/doi/10.1177/2158244015611451

33. Gavrilova, T., Leshcheva, I., Strakhovich, E.: Gestalt principles of creating learning business ontologies for knowledge codification. Knowl. Manag. Res. Pract. 13(4), 418-428 (2015)

34. Haroz, S., Kosara, R., Franconeri, S.L.: ISOTYPE visualization - working memory, performance, and engagement with pictographs. In: Proceedings of the 33rd Annual ACM Conference on Human Factors in Computing Systems - CHI 2015, pp. 1191-1200 (2015). http://dl.acm.org/citation.cfm?id=2702123.2702275

35. Borkin, M.A., et al.: Beyond memorability: visualization recognition and recall. IEEE Trans. Visual Comput. Graphics 22(1), 519-528 (2016)

36. Hall, A., Virrantaus, K.: Visualizing the workings of agent-based models: diagrams as a tool for communication and knowledge acquisition. Comput. Environ. Urban Syst. 58, 1-11 (2016)

37. Zhi, Q., Su, M.: Enhance collaborative learning by visualizing process of knowledge building with padlet. In: International Conference of Educational Innovation through Technology (EITT), vol. 1, pp. 221-225 (2015). http://ieeexplore.ieee.org/document/ $7446182 /$

38. Wang, M., Peng, J., Cheng, B., Zhou, H., Liu, J.: Knowledge visualization for self-regulated learning. Educ. Technol. Soc. 14(3), 28-42 (2011)

39. Marchese, F.T., Banissi, E.: Knowledge Visualization Currents: From Text to Art to Culture. Springer, London (2012). https://doi.org/10.1007/978-1-4471-4303-1

40. Bresciani, S., Ge, J., Niu, Y.: The effect of visual mapping on attitude toward organizational strategy: scale development and application in Europe and China. In: International Conference on Communication, Media, Technology and Design, vol. 2, pp. 275-283 (2014)

41. Diakopoulos, N., Kivran-Swaine, F., Naaman, M.: Playable data: characterizing the design space of game-y infographics. In: Proceedings of the 2011 Annual Conference on Human Factors in Computing Systems, pp. 1717-1726 (2011)

42. Bertschi, S., et al.: What is knowledge visualization? Perspectives on an emerging discipline. In: Proceedings of the International Conference on Information Visualization, pp. 329-336 (2011)

43. Sun, N., Li, K., Zhu, X.: Action research on visualization learning of mathematical concepts under personalized education idea: take learning of geometrical concepts of elementary math for example. In: Cheung, S.K.S., Kwok, L., Shang, J., Wang, A., Kwan, R. (eds.) ICBL 2016. LNCS, vol. 9757, pp. 348-359. Springer, Cham (2016). https://doi.org/10.1007/9783-319-41165-1_31 